\title{
Bioeconomia: Um novo caminho para a sustentabilidade na Amazônia?
}

\author{
Bioeconomy: A new path to sustainability in the Amazon? \\ Bioeconomía: ¿Un nuevo camino hacia la sostenibilidad en la Amazonía?
}

\section{Resumo}

Os pressupostos da segunda lei da termodinâmica alicerçam o entendimento biofísico da teoria econômica, em que evidencia a biodegradação do meio ambiente devido aos efeitos da entropia gerados pela economia. Os acontecimentos mundiais ocorridos entre 1950 e 1970 tornaram mais evidentes os efeitos negativos do padrão econômico dominante. Assim, tornou-se imperativo pensar o meio ambiente em termos mais orgânicos, no sentido de compreender o papel do homem e a importância de suas ações para o desenvolvimento sustentável. Este artigo busca analisar a bioeconomia como um caminho para a sustentabilidade na Amazônia, por ser promissora em conciliar objetivos sociais, econômicos e ambientais. Delimitou-se a área de estudo na Amazônia Legal, ao considerar sua representatividade nacional nas questões que envolvem a sustentabilidade. Como suporte à análise de dados qualitativos e quantitativos, as pesquisas bibliográficas e descritivas permitiram a interpretação dos fenômenos atuais que envolvem a bioeconomia na região. Para apresentar os resultados e discussão, utilizou-se a estatística descritiva do uso de série temporal (2010-2019). Conclui-se que a bioeconomia na Amazônia é promissora para a geração de valor adicionado ao produto nacional, bem como gera emprego local e contribui para os objetivos ambientais por meio de atividades com baixo impacto. Não obstante, há desafios no campo do conhecimento avançado em bioeconomia, bioindústria e infraestrutura necessária para os avanços em todos os níveis.

Palavras-chave: Entropia; Bioeconomia; Sustentabilidade; Amazônia.

\begin{abstract}
The assumptions of the second law of thermodynamics support the biophysical understanding of the economic theory that biodegradation of the environment is due to the effects of the entropy generated by the economy. World events between 1950 and 1970 made more evident negative effects of the dominant economic pattern. Thus, it became imperative to think about the environment in more organic terms to understand the role of human society and the importance of its actions toward sustainable development. As it promises to reconcile social, economic, and environmental objectives, this article seeks to analyze the bioeconomy as a path for sustainability in the Brazilian Amazon. The chosen study area is the Legal Amazon for considering its national relevance in issues involving sustainability. To support the analysis of qualitative and quantitative data, a literature review was carried out for a better interpretation of current phenomena involving the bioeconomy in the region. For results and discussion, descriptive statistics and time series (2010-2019) analyses were used. The study concludes that the Amazonian bioeconomy has the potential to add value to the Brazilian national product, as well as to generate local employment and to contribute towards environmental conservation through activities with low impact. Nevertheless, there are challenges such as the need to advance in the knowledge base and in the required infrastructure to promote development in the region's bioeconomy.
\end{abstract}

Keywords: Entropy; Bioeconomy; Sustainability; Amazon. 


\begin{abstract}
Resumen
Los supuestos de la segunda ley de la termodinámica apoyan la comprensión biofísica de la teoría económica, que hace evidente la biodegradación del medio ambiente como consecuencia de los efectos de la entropía generados por la economía. Los acontecimientos mundiales entre 1950 y 1970 hicieron más evidente los efectos negativos del patrón económico dominante. Por lo tanto, se hizo imperativo pensar en el medio ambiente en términos más orgánicos, para comprender el papel del hombre y la importancia de sus acciones para el desarrollo sostenible. Este artículo busca analizar la bioeconomía como camino hacia la sustentabilidad en la Amazonía, ya que es prometedora en la conciliación de objetivos sociales, económicos y ambientales. Se delimitó el área de estudio a la Amazonía Legal, considerando su representación nacional en temas de sustentabilidad. Para apoyar el análisis de datos cualitativos y cuantitativos, la investigación bibliográfica y descriptiva permitió interpretar los fenómenos actuales relacionados con la bioeconomía en la región. Para presentar los resultados y la discusión se utilizó estadística descriptiva y el uso de series de tiempo (2010-2019). Se concluye que la bioeconomía en la Amazonía es promisoria para la generación de valor agregado al producto nacional, además de generar empleo local y contribuir a los objetivos ambientales a través de actividades de bajo impacto. Sin embargo, existen desafíos en el campo del conocimiento avanzado en bioeconomía, bioindustria y la infraestructura necesaria para los avances en todos los niveles.
\end{abstract}

Palabras clave: Entropía; Bioeconomía; Sustentabilidad; Amazonas.

\title{
1. Introdução
}

Entre as décadas de 1950-1970, observa-se com mais evidência os efeitos negativos do padrão econômico dominante. Tornou-se imperativo pensar o meio ambiente em termos mais orgânicos, no sentido de compreender o papel do homem e a importância de suas ações para o desenvolvimento sustentável. Ocorreram progressos revolucionantes que permitiram a criação de uma nova consciência planetária (Morin, 2003). No campo do conhecimento biotecnológico, surgiram também, pesquisas em diversas áreas, tais como genética, biologia molecular e bioquímica.

Neste contexto, ganhou espaço o desenvolvimento de teorias e modelos que buscaram aproximar a economia da ecologia (Faria \& Pires, 2018). De forma especial, Nicolas Georgescu-Roege trabalhou a fundamentação biofísica da Economia, ao ligar teoria econômica, meio ambiente e realidade social em conjunto. O núcleo da sua abordagem é a segunda lei da termodinâmica. Neste sentido, os pressupostos dessa abordagem demonstram os efeitos do processo entrópico causado pela economia, por meio de uma abordagem orgânica. Estabelece-se assim, um novo caminho para o desenvolvimento sustentável, a bioeconomia (Leff, 2006).

De acordo com a CE (2012, p. 3), a Bioeconomia "abrange a produção de recursos biológicos renováveis e a conversão destes recursos e fluxos de resíduos em produtos de valor acrescentado". Barba \& Santos (2020, p. 04) afirmam que a "natureza é espontaneamente uma economia circular, nela nada se perde, tudo se transforma, se recicla, se renova e assim sucessivamente”. Para Valli, Russo e Bolzani (2018, p. 14), a biotecnologia e os produtos de base biológica têm ganhado atenção devido às fontes renováveis verdes, sendo que o "Brasil pode se tornar um líder em bioeconomia, principalmente por todo o potencial e vantagens que a natureza oferece ao país”. Para a Amazônia, Nobre (2019) destaca que há uma oportunidade emergente para desenvolver uma economia verde, com o aproveitamento do valor de uso de uma floresta produtiva, que, com a ajuda de tecnologias, pode possibilitar um desenvolvimento econômico inclusivo em termos sociais.

Assim, o presente trabalho tem como objetivo analisar a bioeconomia como um caminho para a sustentabilidade na Amazônia, por ser promissora em conciliar objetivos sociais, econômicos e ambientais. Para o desenvolvimento da pesquisa, foi utilizada a pesquisa descritiva e bibliográfica. A primeira teve como objetivo descrever as características da bioeconomia, por meio da relação de suas variáveis e condicionantes globais, regionais e locais. A segunda desenvolveu-se com a pesquisa em livros, artigos científicos nacionais e internacionais que visaram entender as diversas concepções do objeto de estudo, a fim de situar o conhecimento da bioeconomia aplicado à Amazônia.

Na apresentação do conteúdo, o artigo encontra-se dividido em três partes: i) epistemologia ambiental e a ciência econômica; ii) aspectos teóricos da bioeconomia; e iii) bioeconomia: um caminho para a sustentabilidade na Amazônia. 


\section{Metodologia}

Para a delimitação da área de estudo, utilizou-se o conceito de Amazônia Legal, compreendida na Lei $n^{\circ} 5.173$ (1996), que abrange os Estados do Acre, Pará, Amazonas, Amapá, Roraima, Rondônia, Mato Grosso, Goiás e Maranhão. O delineamento teórico do conceito de bioeconomia, bem como a base da epistemologia ambiental permitiram a compreensão do objeto de estudo em conjunto com a análise de dados e interpretação dos fenômenos atuais que envolvem a bioeconomia na Amazônia. Neste contexto, a pesquisa compreende a abordagem descritiva e bibliográfica.

A pesquisa descritiva delineia o que é e aborda quatro aspectos: a descrição, o registro, análise e, interpretação dos fenômenos atuais (Lakatos \& Marconi, 2002). Assim, foram descritas as informações acerca da evolução da bioeconomia no mundo e no Brasil, com a particularidade para a Amazônia; e os dados coletados permitiram a análise dos principais efeitos da bioeconomia na região, o potencial para gerar riquezas e promover caminhos para a sustentabilidade. A pesquisa bibliográfica com base em material já publicado, inclui livros, revistas, dissertações e teses que trataram da literatura geral pertinente à bioeconomia como alternativa de sustentabilidade.

O estudo baseia-se em construções teóricas da epistemologia ambiental e da ciência econômica. Visa-se compreender tal fenômeno na Amazônia, ao analisar a bioeconomia sob uma perspectiva global, regional e local. As características do fenômeno, são expostas a partir da abordagem dedutiva, que visa à compreensão por meio da razão, princípio basilar do conhecimento humano (Pereira, Shitsuka, Parreira \& Shitsuka, 2018).

Os dados analisados foram de natureza qualitativa, principalmente relacionada à cadeia produtiva e geração de valor da bioeconomia, e quantitativos, por envolver números da bioeconomia - geração de empregos. O estudo inclui fontes primárias (dados históricos, bibliográficos, estatísticos, arquivos oficiais, tais como IBGE, RAIS); e fontes secundárias (livros e artigos). Para apresentar os resultados e discussão, utilizou-se a estatística descritiva, com o uso de série temporal (20102019), com o objetivo de reduzir dados graficamente e torná-los mais compreensíveis (Lakatos \& Marconi, 2002).

\section{Resultados e Discussão}

\subsection{Epistemologia ambiental e a ciência econômica}

Ao trazer argumentos da pré-história e da história, Morin (2003) chama atenção às mudanças produzidas pela civilização e seus impactos nas sociedades que viviam desde os tempos remotos nas florestas. A economia tornou-se mundial, juntamente com a mundialização das concorrências e conflitos, característica que ocorre também no mundo das ideias.

A despeito de todos os conflitos, o autor compreende que há um esboço de consciência planetária que se caracteriza pela existência de alguns elementos, tais como a ameaça de uma guerra nuclear; a formação de uma consciência ecológica global, tendo em vista os acontecimentos mundiais que colocaram em evidência o impacto humano sobre o meio ambiente; e a inserção crescente dos problemas do 'terceiro mundo' nas discussões mundiais.

Morin (2003, p. 22) resume os progressos revolucionantes que permitiram a emergência de uma nova consciência planetária. "As ideias que pareciam mais certas sobre a natureza do universo, sobre a natureza da Terra, sobre a natureza da Vida e sobre a própria natureza do homem são subvertidas nos anos 1950-1970, a partir dos progressos concomitantes da astrofísica, das ciências da Terra, da biologia, da paleontologia."

Esses progressos ocorreram no campo do conhecimento biotecnológico, com pesquisas em diversas áreas tais como genética, biologia molecular e bioquímica. Com isso, houve um crescente interesse e expectativas pelo desenvolvimento de uma indústria de biotecnologia, caracterizada como "um novo setor industrial que transformará a sociedade e a economia" (Faria \& Pires, 2018, p. 03). 
Leff (2001, p. 109) afirma a necessidade de associar o saber ambiental a um conjunto de disciplinas, visando “construir um conhecimento capaz de captar a multicausalidade e as relações de interdependência dos processos de ordem natural e social, que determinam as mudanças socioambientais". Por meio desse processo, busca-se "construir um saber e uma racionalidade social orientados para os objetivos de um desenvolvimento sustentável, equitativo e duradouro". Nesse sentido, o autor complementa:

A resolução dos problemas ambientais, assim como a possibilidade de incorporar as condições ecológicas e bases de sustentabilidade aos processos econômicos - de internalizar as externalidades ambientais na racionalidade econômica e os mecanismos de mercado - e construir uma racionalidade ambiental e um estilo alternativo de desenvolvimento, implica na ativação e objetivação de um conjunto de processos sociais (Leff, 2001, p. 111).

Morin (2003) destaca o homem como principal instrumento para mediar as soluções dos problemas ambientais existentes, visando compreender e melhorar esses processos. Coloca o homem no interior da Biosfera, ligado aos ecossistemas existentes, como uma camada de vida nascida da Terra e solidária a ela. Em outros termos, o autor defende que a solidariedade ecológica é uma grande e recente descoberta, visto que nenhum ser vivo pode ser desligado da biosfera, sendo, portanto, componente e responsável. Acerca do papel do homem nesse processo, o autor argumenta:

O homem transformou a Terra, domesticou suas superfícies vegetais, tornou-se senhor de seus animais. Mas não é o senhor do mundo, nem mesmo da Terra. Esse homem deve reaprender a finitude terrestre e renunciar ao falso infinito da onipotente técnica, da onipotência do espírito, de sua própria aspiração à onipotência, para se descobrir diante do verdadeiro infinito que é inominável e inconcebível. Seus poderes técnicos, seu pensamento, sua consciência devem doravante ser destinados, não a dominar, mas a arrumar, melhorar, compreender” (Morin, 2003, p. 176-177).

A consciência do homem acerca desses processos e de compreender a sua relação com a natureza compreende um esclarecimento diante da finitude terrestre. Tal como assevera Kant (1784, p. 6) "um homem pode (...) retardar o esclarecimento em relação ao que ele tem a obrigação de saber; mas renunciar a ele, seja em caráter pessoal, seja ainda mais para a posteridade, significa lesar os direitos sagrados da humanidade”. Esse retardamento é observado pela história, pois só após alguns acontecimentos mundiais, a crise ambiental se tornou tão evidente ao ponto que o homem não considerou mais possível ignorar os seus efeitos.

Leff (2006) argumenta que a crise ambiental se tornou evidente por meio da demonstração da irracionalidade ecológica dos padrões dominantes de produção e consumo. Houve um interesse político e técnico em valorizar a natureza, o surgimento de estratégias de desenvolvimento. Consequências mais gerais desse padrão são as contaminações das águas, lenções freáticos, chuvas ácidas, desertificação, desmatamento, inundações, emissões de $\mathrm{CO}_{2}$ que intensificam o efeito estufa, de forma que transformou a consciência ecológica em consciência do perigo global que ameaça o planeta. "A ecologia tornouse um problema político não apenas local (degradação dos ecossistemas), mas também global (alteração da biosfera)” (Morin, 2003, p. 136)

Nesse sentido, o Relatório de Meadows, encomendado pelo Clube de Roma em 1972, e os acontecimentos na década de 1980, deixaram ainda mais evidente o processo que excedia os limites das fronteiras nacionais. Após 1970 ocorreram outras conferências, a exemplo de Estocolmo - 1972 e do Rio - 1992, que colocaram em discussão a necessidade de conciliar a proteção ecológica com as necessidades de desenvolvimento econômico. Tais conferências de alcance mundial tornam plausível o argumento de pensar a política, a economia, a demografia, a ecologia em termos planetários. Na visão de Morin (2003, p. 159) "trata-se de buscar sempre a relação de inseparabilidade e de inter-retroação entre todo fenômeno e seu contexto, e de todo contexto com o contexto planetário." 
Morin (2000, p. 67) chama a generalização da economia liberal de mundialização, e traz um destaque para a interdependência: "a economia mundial é cada vez mais um todo interdependente: cada uma de suas partes tornou-se dependente do todo e, reciprocamente, o todo sofre as perturbações e imprevistos que afetam as partes.”

Com vistas a essa interdependência, cresceram os debates em torno da necessidade de pensar a economia e a ecologia em termos mais orgânicos. Nesse contexto, emergiu a entropia como lei-limite da racionalidade econômica, sendo esta considerada a quantidade termodinâmica que mede o nível de degradação de energia de um sistema (Leff, 2006).

O autor destaca que os limites do crescimento econômico estabelecidos pela lei-limite da entropia - rege os fenômenos da natureza e conduz o processo irreversível e inelutável da degradação da matéria e energia do universo. Morin (2003, p. 34) vai mais além, e informa o caráter psíquico de interferência do processo econômico na vida, ao afirmar que "seu caráter exponencial não cria apenas um processo multiforme de degradação da biosfera, mas também um processo multiforme de degradação da psicosfera, ou seja, de nossas vidas mentais, afetivas, morais".

Leff (2006) traz como marco para a economia a invenção de modos de produção e diferentes formas de apropriação da natureza, formando excedentes concentrados em determinadas classes. Com o desenvolvimento do transporte naval, intensificaram as relações de intercâmbio e observou-se o auge do capitalismo mercantil e industrial, com intercambio desigual de mercadorias naturais e tecnológicas. A ordem da economia fundada no equilíbrio e no princípio da escassez levou à desnaturalização da natureza e à insustentabilidade do processo de produção.

Nesse sentido, a ciência econômica nasce de uma visão mecanicista (corrente que entende a natureza a partir de sua submissão aos processos mecânicos). Leff (2006) argumenta que um pecado original da economia se deve a essa visão mecanicista, e traz um contraponto com as visões de Nicolas Georgescu-Roege, como crítica ao sistema de racionalidade econômica.

Considerando os limites da ciência econômica e do crescimento, bem como a capacidade de carga e diluição dos ecossistemas, se questionou a racionalidade econômica e a revisão do papel da economia na natureza. O mercado demonstra incapacidade de atribuir valores econômicos à produtividade da natureza e aos serviços ambientais para um desenvolvimento sustentável. Nesse sentido, ganhou espaço o conceito de bioeconomia, visando refundar os princípios do processo econômico com base na lei da termodinâmica (Leff, 2006).

De acordo com Faria \& Pires (2018, p. 03), “acredita-se que até 2050, a população mundial deverá atingir 9 bilhões, o que colocará uma pressão sem precedentes sobre o meio ambiente e seus recursos". Nesse processo, a bioeconomia contribuiria com a geração de energia renovável, conforme destaca o autor:

A bioeconomia promete liderar a próxima onda emergente do desenvolvimento econômico global, tendo como base a energia renovável, matérias-primas renováveis, produtos recicláveis, processos biológicos, organismos naturais ou geneticamente modificados, fermentação, biotecnologia e biologia molecular.

Nesse sentido, a contribuição ocorre por ser a bioeconomia orientada pela inovação, conservação dos recursos naturais, renovação, circularidade e multifuncionalidade, e ainda por gerar empregos, crescimento e prosperidade nas áreas rurais, costeiras e urbanas. Mas para que isso ocorra, é necessário mudar o sistema produtivo mundial, hoje pautado nos monocultivos vegetais, em sistemas mais diversificados, como os Sistemas Agroflorestais ou na forma de Mosaicos, uma vez que o uso de poucas espécies, ao mesmo tempo que destroem ecossistemas terrestres, são muito vulneráveis a pragas e doenças (Oliveira, 2019).

De acordo com Füleky (2009, Figura 1), de um total de 350 mil espécies vegetais, 80 mil são comestíveis, mas apenas cerca de 150 são mais utilizadas pelo ser humano, sendo que 30 delas são responsáveis por 95\% das calorias e proteínas 
consumidas. Citando Füleky (2009), Oliveira (2019) menciona que cerca de metade do consumo mundial vem de apenas quatro espécies de plantas: arroz (Oryza sativa), milho (Zea mays), trigo (Triticum sp) e batata (Solanum tuberosum).

Figura 1. Diversidade de plantas total e usadas pelo ser humano.

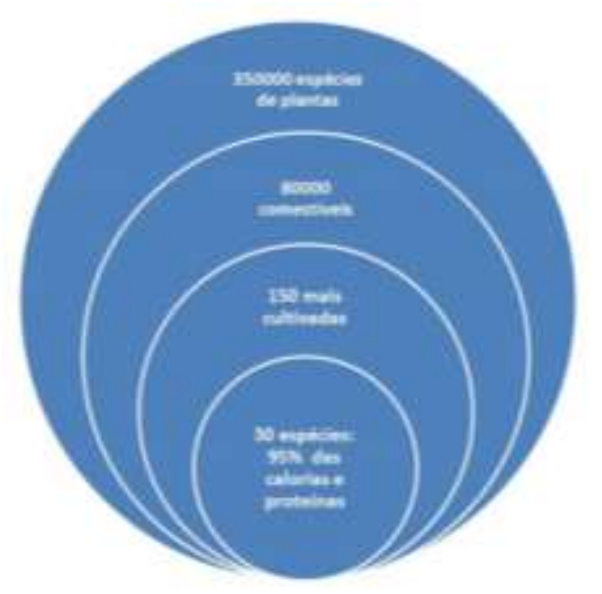

Fonte: Adaptado de Füleky (2009, citado por Oliveira, 2019).

Segundo Oliveira (2019), para que haja um desenvolvimento sustentável capaz de dar suporte à população humana sem colocar em risco os sistemas biológicos do planeta, são necessárias medidas de correção do modelo produtor de alimentos predominante no nosso planeta. Entre as medidas a serem adotadas, segundo esse autor, pode-se citar:

- Redução da população humana de uma forma planejada, com controle de natalidade e orientação governamental às famílias menos esclarecidas, uma vez que a Pegada Ecológica está impactando a Biocapacidade do planeta em suprir as necessidades dos seres humanos (Schaefer et al., 2006; Lamim-Guedes, 2011) ao ponto de deixar um déficit já na década de 1980 (WWF, 2010). Quanto maior a população mundial, maior é o impacto nos ecossistemas do planeta.

- Redução das áreas com monocultivos e aumento das áreas com cultivos mistos envolvendo espécies perenes e animais tentando imitar a diversidade encontrada nas florestas;

- Aumento das áreas de florestas econômicas (reflorestamentos), revertendo parte do processo de desmatamento do planeta;

- Aumento das áreas cultivadas com as cerca de 7000 espécies vegetais conhecidas, enriquecendo a alimentação humana e reduzindo os efeitos de intolerância alimentar na população mundial;

- Recuperação de áreas degradadas recompondo ecossistemas (restauração ambiental) ou com sistemas produtivos (recuperação/ regeneração), aumentando as áreas com florestas e reduzindo o efeito estufa no planeta;

- Socialização do conhecimento universal, preparando melhor a população mundial para as mudanças globais que vêm acontecendo ao longo dos anos.

\subsection{Aspectos teóricos da Bioeconomia}

Em 1850, o matemático alemão Rudolf Clausius lançou as bases para a formulação da segunda lei da termodinâmica, gerando a discussão do conceito de entropia. A abordagem foi desenvolvida, em 1971, por Georgescu-Roegen, por meio da obra The Entropy Law and the Economic Process, por meio da qual o conceito de bioeconomia ou economia ecológica tornouse conhecido (Monte, 2013)

Nicholas Georgescu-Roegen propôs uma teoria visando criar uma economia ecologicamente e socialmente sustentável, por meio da análise questões econômicas associadas à biologia. Não obstante os pensamentos percussores de 
Georgescu, não há um consenso sobre a definição de bioeconomia. Tem evoluído e varia de acordo com autores, "embora existam elementos convergentes, como suas origens em atividades primárias, enfoque transversal e ênfase na produção econômica com o emprego de tecnologias de conversão de produtos cada vez mais avançadas” (Silva, Pereira, e Martins, 2018, p. 283)

De acordo com Leff (2006, p. 181), a bioeconomia proposta por Georgescu-Roegen surge como proposta que assenta as bases para a "compreensão da insustentabilidade da economia a partir do incremento inexorável da entropia nos processos de produção e consumo induzidos pela racionalidade econômica." A bioeconomia se apresenta como uma teoria heurística que vincula a economia às leis da termodinâmica, tendo como maior desafio "integrar o funcionamento da entropia como lei-limite aos processos neguentrópicos geradores da ordem, vida, criatividade e produtividade da natureza.” (Leff, 2006, p. 181).

$\mathrm{O}$ autor defende que a bieconomia baseada nos princípios da termodinâmica deve passar de um conceito crítico para um novo paradigma econômico, a partir de processo neguentrópico e um sistema auto-organizado. Para isso, “é necessário construir o conceito de produtividade ecotecnológica a partir dos sentidos do conceito de entropia no campo da bioeconomia e das estruturas dissipativas". Nesse processo, seriam incorporadas "as condições entrópicas de todo processo de transformação de massa e energia como o processo neguentrópico de formação de biomassa a partir dos processos fotossintéticos da biosfera, para basear neles urna produção sustentável” (Leff, 2006, p. 201)

Esse processo ocorre no contexto da globalização econômico-ecológica, e visa criar novas estratégias teóricas, investigações científicas e prática que utilizem a natureza como fonte ativa de riqueza. Acerca do seu funcionamento, Leff (2006, p. 184) argumenta:

A economia ecológica propôs integrar a economia como um subsistema que opera dentro de um processo mais amplo, que inclui as condições biogeoquímicas e ecológicas da produção. Nesse sentido, o comportamento econômico deveria desenvolver-se como uma extensão dos sistemas vivos, submetendo-se a economia ao sistema mais amplo da ecologia humana, e reconstruindo a racionalidade económica a partir dos princípios da ecologia e da termodinâmica.

Na visão de Leff (2006, p. 179), a "característica peculiar do mundo orgânico é o que faz com que a vida pertença a uma ordem ontológica diferente do resto da natureza e permite que a bioeconomia evite a epistemologia mecanicista". Buscase assim, dar coerência ao conceito de economia por meio da necessidade de assumir o conceito de entropia como potencial e limite do processo econômico na perspectiva da transição para um estado de sustentabilidade ecológica e termodinâmica.

Não obstante as diferentes concepções, observa-se que o conceito de bioeconomia é bastante novo na prática, e começou a ganhar importância na União Europeia, em 2009. Fora da UE, especialmente na Ásia e na África, a bioeconomia ainda não é um tema central. Nagothu (2020) afirma que no mundo desenvolvido, a sustentabilidade ambiental é uma das principais prioridades na busca da bioeconomia, com vistas a alcançar os objetivos do desenvolvimento sustentável. Os impactos da bioeconomia vão além das fronteiras dos países. É necessária uma agenda comum para manter o equilíbrio entre os objetivos econômicos, ambientais e sociais: metas equilibradas, pesquisa e inovação direcionadas, tecnologias acessíveis e de baixo risco na natureza, investimentos garantidos, envolvimento e compromisso das partes interessadas.

De acordo com a CE (2012, p. 3), a Bioeconomia "abrange a produção de recursos biológicos renováveis e a conversão destes recursos e fluxos de resíduos em produtos de valor acrescentado". Utiliza produtos de base biológica e bioenergia, de forma que "os seus setores e indústrias têm um forte potencial de inovação pelo facto de utilizarem um vasto leque de ciências e tecnologias facilitadoras e industriais, juntamente com conhecimentos locais e tácitos.”

O termo bioeconomia inclui "os setores da agricultura, silvicultura, pescas, alimentação e produção de pasta de papel e de papel, bem como setores das indústrias química, biotecnológica e energética." Há um caráter transversal da bioeconomia, 
de forma a se apresentar como oportunidade única para os desafios sociais interligados, tais como segurança alimentar, escassez de produtos, mudança qualitativa em relação aos recursos fósseis e o crescimento sustentável (CE, 2012, p. 4).

Em 2015, a bioeconomia foi definida como a "produção baseada no conhecimento e utilização de recursos biológicos, processos biológicos e princípios para fornecer bens e serviços de maneira sustentável em todos setores econômicos”. Tal definição ocorreu na Primeira Cúpula Global de Bioeconomia em Berlim, a qual destacou que a bioeconomia envolve três elementos: biomassa renovável; tecnologias facilitadoras e convergentes; e a integração entre aplicativos - produção primária, saúde e indústria (FAO, 2016, p. 01)

Um conceito associado é a bioeconomia circular, na qual os nutrientes biológicos são devolvidos à biosfera, diretamente ou em uma cascata de operações consecutivas que otimizam o uso da biomassa. Uma bioeconomia circular também cria oportunidades para os consumidores reduzirem o desperdício geral de alimentos e diminuir o consumo de recursos (FAO, 2019). Nagothu (2020) define a economia circular como o valor dos produtos, materiais e recursos mantidos na economia o mais tempo possível, de forma a reduzir a dependência em relação a novas matérias primas, mantendo a geração de resíduos mínima.

Barba e Santos (2020, p. 04) reforçam que: "a natureza é espontaneamente uma economia circular, nela nada se perde, tudo se transforma, se recicla, se renova e assim sucessivamente". De acordo com o autor, "esse modelo ideal de um sistema econômico circular é o que se pretende atingir através da bioeconomia".

No Brasil, a Confederação Nacional da Indústria focou a definição de bioeconomia na área econômica, notadamente na produção primária, ou agronegócio (plantas e animais e as aplicações veterinárias), produção de biocombustíveis; biotecnologia industrial (produtos químicos, plásticos e enzimas), aplicações ambientais (biorremediação, biossensores), saúde humana (particularmente biotecnologia médica) (Silva, Pereira, e Martins, 2018).

\subsection{Bioeconomia: um caminho para a sustentabilidade na Amazônia}

De acordo com a Global Economy (2020, p. 13), a transição para uma "bioeconomia sustentável será a tarefa conjunta de longo prazo das políticas governamentais, da indústria, da academia e dos cidadãos para encontrar novas abordagens para a boa governança, para buscar sinergias e superar tensões”. Os governos possuem o papel de fornecer estrutura política e estratégias de incentivos, com o apoio e diálogos sociais. “A indústria e os negócios, por outro lado, serão responsáveis por investir em inovações promissoras e negócios emergentes na bioeconomia, enquanto os cidadãos determinarão os padrões de consumo futuros".

A importância da bioeconomia, e de forma mais geral, o desenvolvimento de bioinovações na área da saúde tornou-se ainda mais evidente com a pandemia da COVID-19, trazendo uma relevância ainda maior para as soluções em bioeconomia e seu papel para uma transição efetivamente sustentável:

Impulsionados pelas necessidades de saúde, ferramentas e tecnologias de bioeconomia, novos materiais estão sendo produzidos para o desenvolvimento de vacinas. Combinados com fluxos de trabalho automáticos adaptáveis e flexíveis, as inovações de biotecnologia ajudaram a aumentar nossa capacidade de teste para COVID-19. Novas colaborações industriais e acadêmicas e parcerias globais contribuem ainda mais para melhorar a vigilância de doenças, mas também para desenvolver processos de fabricação novos e avançados para produzir medicamentos e combustíveis que sustentam a sociedade. As crises globais nos fornecem um ímpeto para desenvolver uma estratégia de recuperação econômica baseada na bioeconomia e não na velha ordem econômica baseada no petróleo. Essas mudanças fundamentais na sociedade trazem oportunidades e riscos. As soluções de bioeconomia devem não apenas desempenhar um papel fundamental na reconstrução de uma economia global desmantelada no curto prazo, mas também contribuir para a transição para um sistema econômico e ambiental mais resiliente e sustentável e uma sociedade sustentável e equitativa no longo prazo (Global Bioeconomy, 2020, p. 7). 
Nesse sentido, nota-se a relevância da bioeconomia para o encontro de sinergias entre os setores e a busca por diminuição de riscos de saúde. Barba e Santos (2020) destacam a relevância para o descobrimento de medicamentos, tratamentos e vacinas específicas para cada tipo de doença, em especial a produção de fármacos e biofármacos.

Mejias (2019) argumenta que o mundo passa por um debate sobre como se dará a recuperação econômica pós-crise, e há um caminho convergente e natural do protagonismo brasileiro na área de bioeconomia. Essa tem se mostrado com amplo potencial em vários países, tendo como técnica a biotecnologia em sua maioria. A Finlândia e Holanda investem fortemente em biotecnologia, são referências e pretendem chegar a 100 bilhões de euros em negócios decorrentes da bioeconomia até 2050. O Brasil se destaca na produção de biocombustível, sendo pioneiro e referência mundial.

A busca pela materialização desse novo paradigma de desenvolvimento renovou o interesse dos países pela bioeconomia por meio do fortalecimento das relações entre as atividades do setor primário, como a agricultura e as atividades da indústria. Por essa razão, a bioeconomia tem sido vista como uma oportunidade para a agricultura brasileira utilizar e aprimorar todo o seu potencial de produção de alimentos, fibras, energia e novos produtos ((Silva, Pereira, e Martins, 2018).

Valli, Russo e Bolzani (2018, p. 14) afirmam que a biotecnologia e os produtos de base biológica têm ganhado atenção devido às fontes renováveis verdes, sendo que o "Brasil pode se tornar um líder em bioeconomia, principalmente por todo o potencial e vantagens que a natureza oferece ao país". "O país possui culturas agrícolas de grande extensão, intensa radiação solar, água em abundância, ampla biodiversidade e diversidade de clima. Estes fatores auxiliam no desenvolvimento do Brasil nestas áreas" (Mejias, 2019, p. 08). Acerca da potencialidade brasileira, Fonteyne (2020, p. 40) resume:

O Brasil é a maior potência mundial na bioeconomia. Temos os menores custos e as maiores disponibilidades de biomassa entre os países. Temos a maior biodiversidade do planeta, com $20 \%$ do número total de espécies existentes, o que compreende 116 mil espécies de animais e 55 mil espécies de plantas, cujas propriedades bioquímicas possuem um grande potencial de aproveitamento. É justamente a bioeconomia que pode viabilizar o desenvolvimento sustentável, que alia o setor produtivo à preservação do meio ambiente. Trata-se da nova fronteira do conhecimento humano. É realidade no presente e é, sem dúvida, a economia do futuro. O termo indústria 4.0 não se refere apenas às máquinas e aos sistemas inteligentes. Conectados à indústria 4.0 existem o sequenciamento genético, a nanotecnologia, a economia circular de carbono neutro e a interação nos domínios físico, digital e biológico. A bioeconomia tem íntima relação com a indústria 4.0, o que acena para seu grande potencial.

De acordo com Nobre (2019, p. 07), o Brasil possui uma vantagem em relação às demais nações do globo, que é competitivo em se transformar em uma potência ambiental e se tornar líder mundial em economia circular. "Quando o critério é biodiversidade, somos o número 1 do planeta, seguidos de Colômbia e Indonésia”. De acordo com o autor, o caminho é “mergulhar de cabeça nas infinitas possibilidades da bioeconomia, aliando o conhecimento de nossa biodiversidade às possibilidades da Indústria 4.0”. Nobre cita ainda que é necessário retomar o compromisso com a conservação do planeta, sendo um exemplo para a sociedade global cada vez mais consciente com as questões ambientais.

De acordo com o Silva, Pereira, e Martins (2018), o Brasil conta com vantagens comparativas capazes de proporcionar excelentes oportunidades com o desenvolvimento da bioeconomia:

O país tem a maior diversidade genética vegetal do mundo, contando com 42.730 espécies vegetais distribuídas em seus diferentes biomas (Amazônia, Cerrado, Mata Atlântica, Pampa, Caatinga e Pantanal)". Essa variedade é uma fonte importante para a obtenção de diversos produtos - como biocombustíveis, corantes, óleos vegetais, gorduras, fitoterápicos, antioxidantes e óleos essenciais para o setor produtivo -, que são matérias-primas em indústrias tão diversas como as de higiene e limpeza, alimentos, bebidas, farmacêutica e de cosméticos. No caso dos biocombustíveis produzidos no país, por exemplo, os mais importantes, o etanol e o biodiesel, têm respectivamente a cana-de-açúcar e a soja como suas principais matérias-primas (Silva, Pereira, e Martins, 2018, p. 292). 
Uma mudança positiva para o desenvolvimento da bioeconomia no Brasil foi a publicação da Lei 13.123, de 20 de maio de 2015 - Lei da Biodiversidade, que aperfeiçoou a legislação de acesso ao patrimônio genético local e estimulou o desenvolvimento de cadeias produtivas sustentáveis. Para Silva, Pereira e Martins (2018, p. 320) o "desenvolvimento efetivo da bioeconomia no país requer, além da disponibilidade e de custos competitivos dos insumos físicos, soluções no campo das biociências e em conhecimentos avançados em biotecnologias". Um elemento crítico será a necessidade de melhorias nas capacitações locais para utilizar os recursos do país, desenvolver e empregar novas tecnologias.

Considerando a potencialidade e as características da bioeconomia, há um aumento de agentes econômicos e políticos defendendo a proposta como um caminho para o desenvolvimento da Amazônia. Kohlmann \& Ferreira (2020) citam a agenda do Instituto Escolhas, por meio da criação de incentivos econômicos, avanços em Pesquisa, Desenvolvimento e Inovação (PD\&I), infraestrutura e engenharia financeira. Há ações voltadas para o desenvolvimento da oferta e produção, com a capacitação e treinamento com foco nas comunidades locais e produtores, certificação, segurança jurídica; ações voltadas para o desenvolvimento da demanda por meio da inserção nas cadeias globais de valor, desenvolvimento comercial; e ações voltadas para a proteção da biodiversidade.

Nobre (2019) destaca que a Amazônia é uma oportunidade emergente para desenvolver uma "economia verde", com o aproveitamento do valor de uso de uma floresta produtiva, que, com a ajuda de tecnologias, pode possibilitar um desenvolvimento econômico inclusivo em termos sociais. É possível a geração de bioindústrias locais e diversificados e gerar produtos de valor agregado. Acerca das possibilidades, o autor destaca:

É possível criar as condições para o florescimento de uma bioeconomia vibrante e inclusiva, que respeite a floresta e seus rios, a fauna, a flora e os povos tradicionais amazônicos, mas os desafios não são poucos nem pequenos, entre eles o fato de a Amazônia ainda estar em grande medida desconectada dos centros de inovação tecnológica 4.0 e de bioeconomia mais avançados do planeta (Nobre, 2019, p. 09)

A Embrapa tem uma atuação bastante robusta na Amazônia legal: "são nove unidades de pesquisa, que reúnem 335 pesquisadores e 220 projetos em execução, abrangendo investimentos da ordem de R \$ 85,7 milhões" Trata-se de "uma nova perspectiva de economia verde, de baixo carbono, que aproveita os recursos naturais disponíveis para a geração de alimentos, fármacos, bioinsumos e energia". "A bioeconomia é uma das prioridades na gestão de Pesquisa, Desenvolvimento e Inovação (PD\&I) da Embrapa e, dentro desse contexto, a Amazônia se destaca como primeiro cenário para a concentração de esforços". (Embrapa, 2020, p. 01).

O panorama da bioeconomia na Amazônia envolve o fato de a região deter 24,5\% da fauna e $11,2 \%$ da flora brasileira; o açaí, a castanha e o cacau são produzidos em cinco estados da região norte em área muito menor do que a utilizada para a produção de soja; um bioma com diversidade biológica ainda pouco conhecido, com usos mais restrito ao setor de alimentos e bebidas. Quanto às oportunidades, observa-se uma vantagem comparativa em bioprodutos; diversidade; potencial de expansão para setores com importância econômica elevada (Instituto Escolhas, 2019)

Há iniciativas do SEBRAE em andamento com o programa "Inova Amazônia", uma iniciativa "que busca potencializar o empreendedorismo na Amazônia Legal a partir da bioeconomia, reunindo o que há de mais inovador em sustentabilidade e atuando para promover o desenvolvimento territorial.”. Entre os benefícios da bioeconomia há geração de emprego, renda e lucro para o país; novos modelos de negócio; combate à exploração descontrolada dos recursos florestais; possibilidade de criar um ambiente corporativo e a inovação; acelerar a transição de uma economia tradicional para uma pautada no desenvolvimento sustentável (Sebrae, 2019). 
Acerca da geração de empregos, a Figura 2 demonstra o número de empregos gerados nos setores da Bioeconomia extrativo mineral, agropecuária, extração vegetal, caça e pesca, nos Estados da Amazônia Legal. Há uma tendência de crescimento na sua participação entre 2010 e 2019, conforme segue.

Figura 2. Número de empregos - Setor extrativo mineral, agropecuária, extração vegetal, caça e pesca da Amazônia Legal.

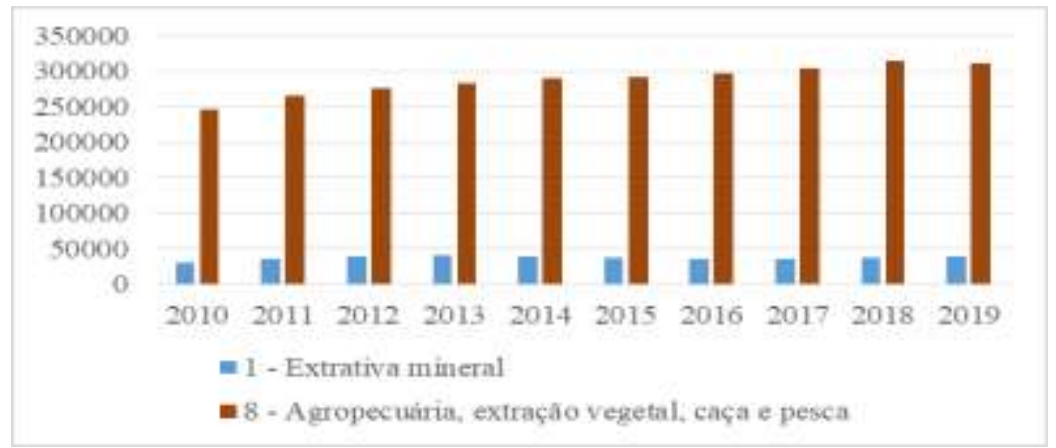

Nota. A figura traz a evolução do número de vínculos efetivos em 31/12 de cada ano nos Estados da Amazônia Legal. Nota-se um crescimento dos empregos na agropecuária, extração vegetal, caça e pesca e certa estabilidade do setor extrativo mineral. Fonte: Rais (2019).

Acerca da sua participação na geração total de empregos, há uma participação maior da agropecuária, extração vegetal, caça e pesca, com um percentual em torno de 5\%, com o setor extrativo vegetal abaixo de $1 \%$, como observa-se na Figura 3.

Figura 3. Percentual de participação do setor extrativo mineral, agropecuária, extração vegetal, caça e pesca da Amazônia legal em relação aos empregos totais.

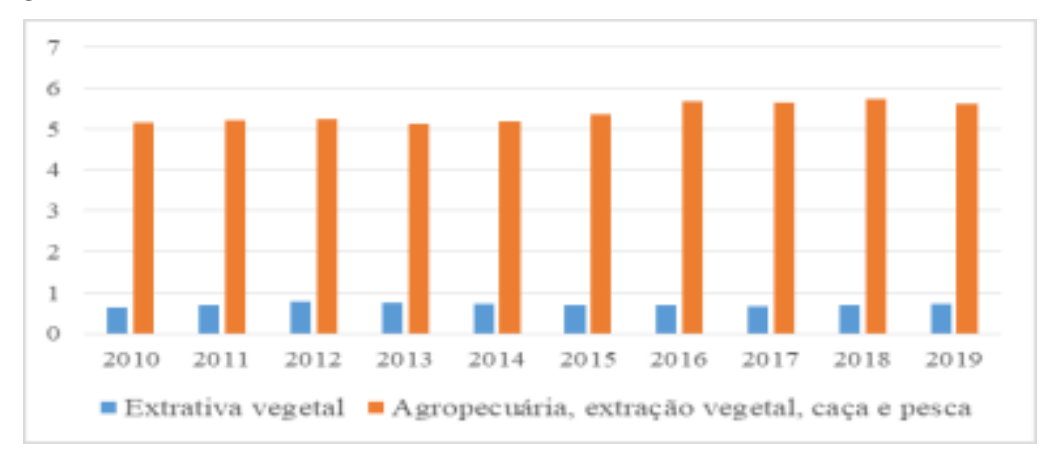

Nota. Observa-se que a participação dos empregos no setor extrativo mineral é menos de 1\% na série histórica 2010-2019. A participação da agropecuária, extração vegetal, caça e pesca mostra-se mais relevante, em torno de $5 \%$ no período analisado.

Fonte: Rais (2019).

De acordo com a ABC (2020) há muitas evidências de que a bioeconomia pode ser inclusiva e lucrativa para os povos da Amazônia e para o Brasil (Figura 4). Há indústrias do açaí, do cacau e das castanhas brasileiras, com grande potencial ainda subaproveitado. Ricardo Abramovay destacou os Estados Unidos investem 5\% do seu PIB, em torno de um trilhão de dólares. No Brasil, a bioeconomia é muito pouco explorada, sendo uma perda não só pelas oportunidades econômicas já conhecidas, como também das potenciais oportunidades. Uma estratégia é o investimento em educação, ciência e tecnologia na região. 
Research, Society and Development, v. 10, n. 10, e41101018545, 2021

(CC BY 4.0) | ISSN 2525-3409 | DOI: http://dx.doi.org/10.33448/rsd-v10i10.18545

Figura 4. Extração vegetal - percentual do volume de produção na Amazônia Legal (2000-2019).

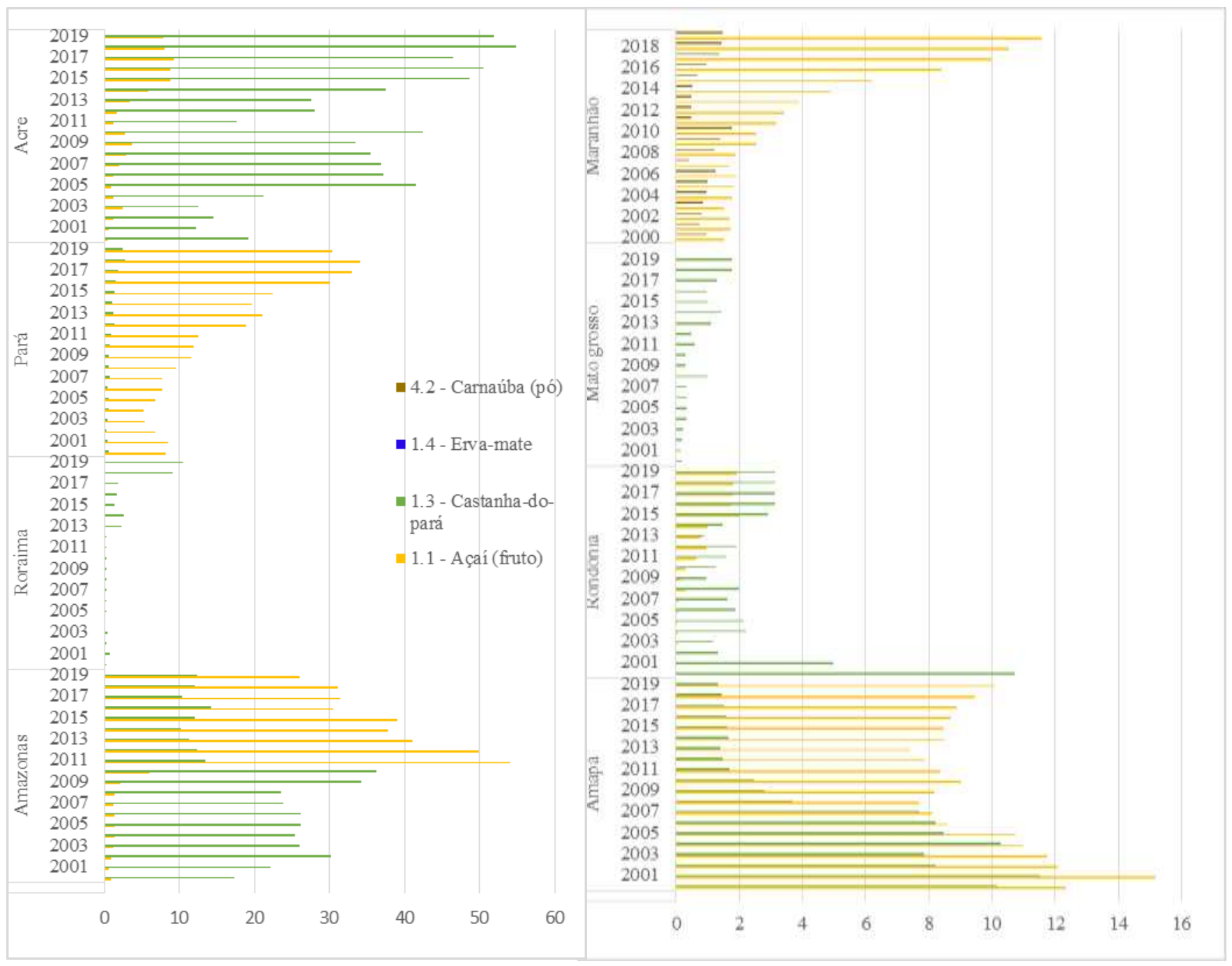

Nota: A série histórica 2000 a 2019 demonstra que os principais produtos de extração vegetal na Amazônia legal são o Açaí e a Castanha-doPará, em percentual do volume de produção. Destaca-se no Amazonas e Pará a produção de açaí; no Acre a produção de castanha; no Amapá ambos os produtos são relevantes; e o Maranhão traz a carnaúba e açaí na composição da extração. Goiás não consta no gráfico por não ter apresentado produção no período.

Fonte: IBGE (2019). Produção da Extração vegetal

Um programa de destaque, instituído pela Superintendência da Zona Franca de Manaus (Suframa) é o Programa Prioritário de Bioeconomia, como estratégia diversificar e impulsionar investimentos no contexto da política de incentivos fiscais. Abrange soluções para a exploração econômica sustentável da biodiversidade (IDESAM, 2020).

Mourão (2020, p. 15) destaca que a "a tríplice hélice entre governo, empresas e universidades poderá ser o motor de propulsão da bioeconomia e demais empreendimentos que visem à produção de bens e serviços". Simão (2020, p. 31) afirma que a "A Amazônia é um loco estratégico na construção de aliança em torno deste modelo econômico. Essa região tem sido apontada como uma nova fronteira econômica, de desenvolvimento de uma "economia verde", equitativa e socialmente inclusiva". Na mesma via, o autor defende uma sinergia entre as instituições de ensino, o setor produtivo e a sociedade civil organizada:

É importante estimular um modelo de desenvolvimento sustentável para a região, agregando novos conhecimentos e estabelecendo diálogo com o conhecimento tradicional, com tecnologia de ponta e com modelos de negócios 
inovadores, apontando formas de financiamento e investimento inovadoras que estimulem a agregação de valor à biodiversidade da região associada à sua conservação e à geração de emprego e renda (Simão, 2020, p. 32)

Freitas e Schor (2020, p. 22-23) orientam que no Estado do Amazonas, assim como em outros territórios similares em biomas, a bioeconomia deve estar associada à sustentabilidade socioambiental e ao conhecimento do bioma e de seu povo. "O conhecimento da sociobiogeodiversidade é elemento fundamental e estruturante da bioeconomia na região amazônica". É necessário compreender que o bioma amazônico conservado é uma vantagem comparativa, assim como o modelo da Zona Franca de Manaus. Os autores citam a bolsa de mercadorias da Amazônia como um instrumento financeiro para fins socioambientais com o "potencial de operacionalizar a bioeconomia amazônica, fomentar o desenvolvimento sustentável e justo e erradicar a pobreza entre as populações produtoras e extrativistas do bioma amazônico”. Não obstante, há desafios:

Gargalos e ineficácias dos projetos e iniciativas, que já foram implementados no estado para desenvolver as cadeias produtivas, são latentes. Empoderar os extrativistas/produtores e trazer segurança de fornecimento às indústrias que desejam agregar valor à sociobiodiversidade amazônica continua sendo um enorme desafio (Freitas \& Schor, 2020, p. 22-23).

A Figura 5 traz uma síntese da cadeia de valor da Bioeconomia, em termos de valor agregado e volume de sua utilização:

Figura 5. Cadeia de valor em Bioeconomia.
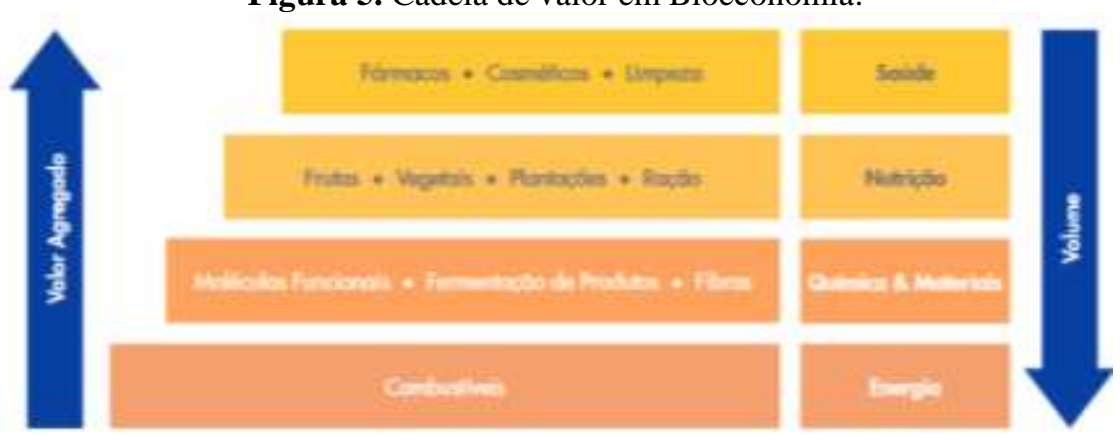

Nota 1. A cadeia de valor da Bioeconomia sintetiza a sua importância estratégica para o Brasil e particularmente para Amazônia, por meio da geração de valor agregado. Nota-se ainda um volume baixo de utilização na área de saúde e nutrição, porém os avanços são relevantes. Fonte: CNI (2013).

Dessa forma, o sucesso da implementação da bioeconomia no mundo apresenta desafios, que envolve a "agregação de valor local, logística e transporte, marketing, campanhas de conscientização voltadas para consumidores, fabricantes e comercialização (FAO, 2019, p. 14)”. Nagothu (2020) afirma que para alcançar a bioeconomia sustentável, há pré-requisitos técnicos, econômicos e sociais, que a própria bioeconomia não é capaz de criar, o que envolve, em geral, tecnologia avançada e suficiente biomassa disponível.

Kohlmann e Ferreira (2020, p.48) citam que os gargalos e os desafios para o destravamento da bioeconomia são conhecidos: "pouco financiamento, baixa utilização de PD\&I, pouca integração industrial, inseguranças e incertezas jurídicas e regulatórias, acesso da base (comunidades e produtores) a ações de incentivo e suporte".

Nesse sentido, nota-se que a bioeconomia é uma oportunidade real que envolve a colaboração entre o estado, setores empresariais, acadêmico e sociedade civil com vistas a formação de uma massa crítica de pesquisadores e lideranças científicas. A Amazônia desponta com uma janela de oportunidades que abre espaço para o desenvolvimento da bioeconomia em escala, respeitando os critérios sociais, econômicos e ambientais de sustentabilidade, aspirações do novo milênio. 


\section{Considerações Finais}

A mundialização da economia trouxe impactos sociais, ambientais, sobretudo, humanos que foram sentidos em escala planetária. A formação de uma nova consciência ecológica global tornou-se relevante para discutir e alterar os rumos em direção a concepções mais globais, orgânicas e ações para uma solidariedade ecológica. Dessa forma, não é mais possível o homem ignorar, e até mesmo, retardar mais ainda o esclarecimento quanto as questões ambientais, em relação a sua obrigação de saber e agir.

A generalização do conhecimento da relação entre economia e ecologia abriu espaço e campo para o desenvolvimento da bioeconomia. Um conceito relativamente novo, mas que vem ganhando espaço na economia mundial, por meio do aumento de sua participação nos produtos internos das nações.

O Brasil, por sua aptidão natural para o desenvolvimento da bioeconomia, possui uma potencialidade de desenvolver e se destacar no cenário mundial com esse novo padrão de desenvolvimento, tendo em vista que este visa conciliar os objetivos sociais, econômicos e ambientais e estão alinhados com as aspirações do desenvolvimento sustentável do novo milênio.

Destaque especial para a bioeconomia é a Região Amazônica, por ser rica em biodiversidade, em material genético para o aprofundamento de pesquisas que levem em conta os conhecimentos tradicionais dos povos da região. Há espaço para a geração de renda local, com respeito ao meio ambiente, e que poderá ser ampliado em escala nacional e global. Faz-se necessário a geração de um arcabouço legal, uma convergência entre os setores público, privado, academia e sociedade civil visando consolidar esse padrão endógeno de desenvolvimento.

Em relação aos aspectos sociais, econômicos e ambientais, a bioeconomia contribui com a geração de empregos na economia Amazônica, pode gerar valor agregado no PIB por meio de sua cadeia de valor e ainda contribui com os objetivos ambientais, em virtude do baixo impacto negativo que causa na natureza. Notou-se com o estudo, que a extração vegetal é relevante em vários Estados da Amazônia Legal, o que pode contribuir de sobremaneira para o alcance de novas perspectivas para o setor por meio da utilização do conhecimento local já existente.

Nesse sentido, cada vez mais a bioeconomia se torna um caminho e uma realidade na Amazônia, na medida em que crescem os interesses e iniciativas práticas do setor, que deverá ser ainda mais aprofundado com o engajamento de todos os envolvidos, visando consolidar um padrão de desenvolvimento sustentável para a região.

\section{Referências}

ABC (2020). Tag: Amazônia 4.0. Academia Brasileira de Ciências. http://www.abc.org.br/tag/amazonia-4-0/.

Barba, R. Y. B. \& Santos, N. (2020). A Bioeconomia no século XXI: Reflexões sobre Biotecnologia e Sustentabilidade no Brasil. Revista de Direito e Sustentabilidade. Organização Comitê Científico Double Blind Review pelo SEER/OJS. https://www.indexlaw.org/index.php/revistards/article/view/7023/pdf

CE (2012). Inovação para um Crescimento Sustentável: Bioeconomia para a Europa. Comissão Europeia. Bruxelas, 13.2 .2012 com 60 final. https://eurlex.europa.eu/legal-content/PT/TXT/PDF/?uri=CELEX:52012DC0060\&from=EN

CNI (2013). Bioeconomia: uma agenda para o Brasil. Brasília: Confederação Nacional da Indústria, 40 p. il. ISBN 978-85-7957-101-51. Bioeconomia. https://static.portaldaindustria.com.br/media/filer_public/78/86/7886aeb1-57a8-4be2-9ad9-f8f31b176a8f/bioeconomia_uma_agenda_para_brasil.pdf

Embrapa (2020). Ciência aposta na bioeconomia para fomentar o desenvolvimento sustentável da Amazônia. Empresa Brasileira de Pesquisa Agropecuária. https://www.embrapa.br/busca-de-noticias/-/noticia/53943113/ciencia-aposta-na-bioeconomia-para-fomentar-o-desenvolvimento-sustentavel-da-amazonia.

FAO (2016). How sustainability is adressed in oficial bioeconomy Strategies at International, National and Regional Levels an Overview. Food and Agriculture Organization of the United Nations. ISBN 978-92-5-109364-1, Rome. http://www.fao.org/3/a-i5998e.pdf.

FAO (2019). Towards Sustainable Bioeconomy: Lessons learned from case studies. Food and Agriculture Organization of the United Nations. http://www.fao.org/3/ca4352en/ca4352en.pdf.

Faria, E. O. \& Pires, C (2018). Economia Circular e Bioeconomia: Como as Abordagens se Relacionam? Centro de Desenvolvimento Sustentável, CDS/UnB, Brasília. http://www.advancesincleanerproduction.net/7th/files/sessoes/6B/6/faria_and_caldeira-pires_academic.pdf 
Fonteyne, A. (2020). Bioeconomia e a Relação com a Indústria 4.0: Grande Potencial. Interesse Nacional. Ano 13. Edição especial 01. Bioeconomia. (pp 3839). https://acervo.socioambiental.org/sites/default/files/documents/prov94.pdf.

Freitas, N. F. \& Schor, T. (2020). Bioeconomia e a Bolsa de Mercadorias da Amazônia. Em Interesse Nacional. Ano 13. Edição especial 01. Bioeconomia (pp 20-25). https://acervo.socioambiental.org/sites/default/files/documents/prov94.pdf

Füleky, G. (2009). Cultivated plants, primarily as food sources. 1, 372p, Encyclopedia of Life Support Systems.

Global Economy (2020). Expanding the Sustainable Bioeconomy: Vision and Way Forward. Communiqué of the Global Bioeconomy Summit 2020. Berlin. https://gbs2020.net/wp-content/uploads/2020/11/GBS2020_IACGB-Communique.pdf.

IBGE (2019). Produção da extração vegetal (2000 - 2019). Instituto Brasileiro de Geografia e Estatística. https://www.ibge.gov.br/estatisticas/economicas/ag ricultur a-e-pecuaria/9105-producao-da-extracao-vegetal-e-da-silvicultura.html?=\&t=series-historicas

IDESAM (2020). Programa Prioritário de Bioeconomia contrata assistente de campo para projeto de PD\&I. Instituto de Conservação e Desenvolvimento Sustentável do Amazonas. https://idesam.org/conteudo/oportunidades-2/programa-prioritario-de-bioeconomia-contrata-assistente-de-campo-para-projeto-depdi/

Instituto Escolhas (2019). Uma nova economia para o Amazonas: Zona Franca de Manaus e Bioeconomia. São Paulo. <https://www.escolhas.org/wpcontent/uploads/2019/10/Uma-nova-economia-para-o-Amazonas_ZFM-e-Bioeconomia-1.pdf.>

Kant, I. (1893). Resposta à pergunta: O que é o esclarecimento? Trans. Luiz Paulo Rouanet, 1783.

Kohlmann, G. \& Ferreira, J. (2020). Como Destravar a Bioeconomia na Amazônia. Interesse Nacional. Ano 13. Edição especial 01. Bioeconomia. (p 40-46). https://acervo.socioambiental.org/sites/default/files/documents/prov94.pdf

Lakatos, E. M. \& Marconi, M. A. (2002). Técnicas de pesquisa: planejamento e execução de pesquisas, amostragens e técnicas de pesquisas, elaboração, análise e interpretação de dados. 5. ed. - São Paulo: Atlas. https://www.academia.edu/33781900/Marconi_Lakatos_Tecnicas_de_Pesquisa.

Lamim-Guedes, V. (2011). Pegada ecológica: consumo de recursos naturais e meio ambiente. Educação Ambiental em Ação, 38:1-9. http://www.revistaea.org/artigo.php?idartigo=1168

Leff, H. (2006). Racionalidade ambiental: a reapropriação social da natureza. Trans. Luís Carlos Cabral. - Rio de Janeiro: Civilização Brasileira.

Leff, H. (2001). Epistemologia ambiental. Tradução Sandra Valenzuela; revisão técnica de Paulo Freire Vieira. Cortez.

Lei $\mathrm{n}^{\circ}$ 5.173, de 27 de outubro de 1966 (1966). Dispõe sobre o Plano de Valorização Econômica da Amazônia; extingue a Superintendência do Plano de Valorização Econômica da Amazônia (SPVEA), cria a Superintendência do Desenvolvimento da Amazônia (SUDAM), e dá outras providências. Brasília, DF. http://www.planalto.gov.br/ccivil_03/leis/15173.htm

Mejias, R. G. (2019). Bioeconomia e Suas Aplicações. $R$. ÎANDÉ Ciências e Humanidades. 2, 105-121, https://periodicos.ufabc.edu.br/index.php/iande/article/view/87/72.

Monte, A. L. Z. (2013). Sintropia em agroecossistemas: subsídios para uma análise bioeconômica. Dissertação de Mestrado Profissional em Desenvolvimento Sustentável https://repositorio.unb.br/bitstream/10482/15763/1/2013_AndreLuisZanelaMonte.pdf

Morin, E. (2003). Terra-Pátria. Traduzido por Paulo Azevedo Neves da Silva. Sulina.

Morin, E. (2000). Os sete saberes necessários à educação do futuro. Trans. Catarina Eleonora F. da Silva e Jeanne Sawaya; Revisão técnica de Edgard de Assis Carvalho. (2a ed.), Cortez; UNESCO.

Mourão, H. (2020). Amazônia: a Nova Fronteira da Bioeconomia. Interesse Nacional. Ano 13. Edição especial 01. Bioeconomia. (p. 40-46). https://acervo.socioambiental.org/sites/default/files/documents/prov94.pdf

Nagothu, U. S. (2020). The Bioeconomy Approach: Constraints and Opportunities for Sustainable Development Routledge Studies in Food, Society and the Environment. Routledge.

Oliveira, L. A. (2019). Sustentabilidade e desenvolvimento. In: GEEA: Grupo de Estudos Estratégicos Amazônicos. Caderno de debates.1 ed. Manaus: Editora INPA, 2019, 15, 33-52.

Pereira, A. S., Shitsuka, D. M., Parreira, F. J. \& Shitsuka, R. (2018). Metodologia da pesquisa científica. UFSM. https://repositorio.ufsm.br/bitstream/handle/1/15824/Lic_Computacao_Metodologia-Pesquisa-Cientifica.pdf?sequence=1.

RAIS (2019). Relação Anual de Informações Sociais. https://bi.mte.gov.br/scripts10/dardoweb.cgi

Schaefer, F., Luksch, U., Steinbach, N., Cabeça, J. \& Hanauer, J. (2006). Ecological Footprint and Biocapacity. European Commission. 11p. https://ec.euro pa.eu/eurosta t/documents/38 88793/5835641/KS-AU-06-001-EN.PDF

Sebrae (2019). Inova Amazônia estimula desenvolvimento com sustentabilidade. Serviço Brasileiro de Apoio às Micro e Pequenas Empresas.http://webcache.googleusercontent.com/search?q=cache:Y-iq0Awli9YJ:www.sebrae.com.br/sites/PortalSebrae/artigos/inovacao-aberta-parageracao-de-bionegocios-na-amazonia,4376c248f14ec610VgnVCM1000004c00210aRCRD+\&cd=1\&hl=pt-BR\&ct=clnk\&gl=br\&client=firefox-b-d

Silva, M. F. O., Pereira, F. S. \& Martins, J. V. B. (2018). A Bioeconomia Brasileira em Números. BNDES Setorial 47, $277-332$. https://web.bndes.gov.br/bib/jspui/bitstream/1408/15383/1/BS47_Bioeconomia_FECHADO.pdf. 
Research, Society and Development, v. 10, n. 10, e41101018545, 2021

(CC BY 4.0) | ISSN 2525-3409 | DOI: http://dx.doi.org/10.33448/rsd-v10i10.18545

Simão, M. O. A. R. (2020). O papel da Universidade na Amazônia na Geração de Conhecimento para Estimular uma Economia da Floresta. Interesse Nacional. Ano 13. Edição especial 01. Bioeconomia (p. 26-30). https://acervo.socioambiental.org/sites/default/files/documents/prov94.pdf.

Valli, M., Russo, H. M. \& Bolzani, V. S. (2018). The potential contribution of the natural products from Brazilian biodiversity to bioeconomy. Anais da Academia Brasileira de Ciências. 90(1 Suppl. 1): 763-778. https://www.scielo.br/pdf/aabc/v90n1s1/0001-3765-aabc-201820170653.pdf

WWF (2010). Living Planet Report 2010: Biodiversity, biocapacity and development. 57 p. World Wide Fund for Nature.https://fdocuments.in/doc ument/living-planet-report-2010-56f1bfd9a410f.html 